\title{
Doses crescentes de corretivo na formação de mudas de mogno (Swietenia macrophylla King) ${ }^{1}$
}

\author{
André Rogério Matos da SILVA², Carlos Alberto Franco TUCCI ${ }^{3}$, Hedinaldo Narciso LIMA ${ }^{4}$, Antenor \\ Francisco de FIGUEIREDO 5
}

\begin{abstract}
RESUMO
A produção de mudas é uma das fases mais importantes do cultivo de espécies arbóreas, sendo essa fase fundamental para o desenvolvimento adequado dessas espécies. O estudo teve como objetivo avaliar o crescimento e a absorção de nutrientes em mudas de mogno sob o efeito de doses crescentes de corretivo. O experimento foi conduzido no período de setembro de 2002 a agosto de 2003. Os tratamentos foram doses crescentes de uma mistura de carbonato de cálcio e carbonato de magnésio p.a., na proporção de $4: 1$, em doses equivalentes a $0 ; 0,5 ; 1,0 ; 2,0 ; 2,5 ; 3,0$ e 5,0 t/ha. O delineamento experimental foi o de blocos ao acaso, com cinco repetiçôes, num total de 35 parcelas, cada formada por 3 plantas. O substrato foi adubado com doses equivalentes a 200-500-300 $\mathrm{kg} . \mathrm{ha}^{-1}$ de $\mathrm{N}, \mathrm{P}_{2} \mathrm{O}_{5}$ e $\mathrm{K}_{2} \mathrm{O}$, respectivamente e $15 \mathrm{~kg}$.ha- ${ }^{-1}$ de micronutrientes FTE- $\mathrm{Br} 12$. As características de crescimento avaliadas foram: altura, diâmetro do colo, matéria seca da parte aérea, raiz e total, relação parte aérea/raiz. Determinaram-se os teores de nutrientes da parte aérea, raiz e total, e em função desta última, estimaram-se os conteúdos. As médias foram comparadas pelo teste de Tukey a $5 \%$ de probabilidade. A calagem afetou todas as características de crescimento, exceto a altura. O requerimento nutricional obedeceu à ordem decrescente de $\mathrm{K}>\mathrm{N}>\mathrm{Ca}>\mathrm{Mg}>\mathrm{P}>\mathrm{Fe}>\mathrm{Mn}>\mathrm{Zn}>\mathrm{Cu}$. A dose de $0,5 \mathrm{t} / \mathrm{h}$ mostrou-se mais vantajosa economicamente e pode ser recomendada quando se utiliza subsolo ácido e de baixa fertilidade natural como substrato.
\end{abstract}

\section{PALAVRAS-CHAVE}

Calagem, substrato, mogno.

\section{Growing doses of liming on mahogany (Swietenia macrophylla King) seedling formation ${ }^{1}$}

\section{ABSTRACT}

Seedling production is one of the more important phases on the cultivation of trees, with this phase being essential for their appropriate development. The study had the objective of evaluating the growth and the absorption of nutrients in mahogany (Swietenia macrophylla King) seedling under the effect of corrective growing doses. The experiment was carried out from September 2002 to August 2003. The treatments were, $0 ; 0.5 ; 1.0 ; 2.0 ; 2.5 ; 3.0$ and 5.0 t/ha, of a mixture of calcium carbonate and magnesium carbonate p.a., in the $4: 1$ proportion. The experimental design was randomized blocks with 5 repetitions, in a total of 35 parcels, each one with 3 plants. The substratum was fertilized with equivalents doses to 200-500-300 kg. ha ${ }^{-1}$ of $N, P_{2} O_{5}$ and $\mathrm{K}_{2} \mathrm{O}$, respectively and $15 \mathrm{~kg}$. ha ${ }^{-1}$ of micronutrients FTE-Br12. The growth characteristics evaluated were height, diameter of the stem, dry biomass of the aerial part, root and total, aerial part/ root relation. It was determined the moisture contents of the aerial part, root and total and as a function of the last one it was estimated the contents. The averages were compared by the test of Tukey using $5 \%$ of probability. The liming affected all the growth characteristics, except the height. The nutritional necessity followed a decreasing order of $K>N>C a>M g>P>F e>M n>Z n>C u$. The dose of 0.5 t.ha ${ }^{-1}$ was more advantageous from the economic point of view and can be recommended to acid subsoil of low natural fertility to compose substratum.

\section{KEYWORDS}

Liming, substratum, mahogany.

\footnotetext{
${ }^{1}$ Parte da dissertação de mestrado do primeiro autor, apresentada ao Programa de Pós-Graduação em Ciências Florestais e Ambientais da UFAM

${ }^{2}$ Engenheiro Florestal, Ms.c. Professor da Escola Agrotécnica Federal de São Gabriel da Cachoeira/AM - arogerioms@hotmail.com

${ }^{3}$ Engenheiro Agrônomo, Dr. Professor Titular DEAS/FCA/UFAM - ctucci@ufam.edu.br

${ }^{4}$ Engenheiro Agrônomo, Dr. Professor Adjunto DEAS/FCA/UFAM - hedinaldo@ufam.edu.br

${ }^{5}$ Engenheiro Agrônomo, Dr. Professor Titular DPAV/FCA/UFAM - antenor@ufam.edu.br
} 


\section{INTRODUÇÃo}

A produção de mudas é uma das fases mais importantes do cultivo de espécies arbóreas. Mudas de qualidade adequada são fundamentais no crescimento e desenvolvimento dessas espécies. Para que se produzam mudas de qualidade é necessário o conhecimento das características das espécies, notadamente seus requerimentos nutricionais e suas respostas à correção do substrato e à adição de fertilizantes (Carneiro, 1995).

A terra de subsolo, geralmente isenta de sementes de plantas indesejáveis e microrganismos patogênicos, é um dos materiais mais usados como substrato para produção de mudas, principalmente por pequenos produtores rurais. No entanto, $o$ substrato originado de terra do subsolo, em geral, éácido e de baixa fertilidade natural, características que podem ser corrigidas por meio da calagem e fertilização mineral (Paiva \& Gomes, 2000).

O uso de corretivos e fertilizantes é, portanto, uma prática fundamental no processo de formação de mudas, não só para a redução da acidez do solo, mas também como fonte de nutrientes indispensáveis ao crescimento inicial das plantas, especialmente quando se utiliza na preparação de substrato para produção de mudas material de solos ácidos e pobres em nutrientes.

A acidez elevada e a pobreza em nutrientes são características comuns aos solos de terra firme da Amazônia brasileira. Portanto, as espécies que se desenvolvem nesse ambiente são geralmente bem adaptadas a essas condições, desenvolvendo-se bem mesmo sob tais limitaçôes. Todavia, quando se pretende intensificar o cultivo de determinadas espécies é fundamental reduzir as limitações químicas, a fim de promover o crescimento com maior rapidez e aumentar o índice de estabelecimento das mudas no campo.

Por outro lado, é fundamental conhecer a quantidade de corretivo a ser aplicada ao substrato, uma vez que essa depende das características do corretivo a ser aplicado, das propriedades químicas do solo, especialmente aquelas relacionadas à acidez, $\mathrm{e}$ das características das espécies a serem cultivadas, haja vista que essas respondem de forma diferenciada sendo, em diferentes graus, tolerante ou susceptível à acidez do solo. Além disso, a utilização de doses excessivas de corretivo pode causar problemas maiores do que aqueles ocasionados pela acidez dos solos (Tucci, 1996).

A correção do solo visa, especialmente, corrigir a acidez, diminuir efeitos tóxicos de $\mathrm{Al}^{3+}, \mathrm{Mn}^{2+} \mathrm{e} \mathrm{Fe}^{2+}$ e elevar os teores de $\mathrm{Ca}^{2+}$ e $\mathrm{Mg}^{2+}$ no solo (Raij, 1991; Tucci, 1996). No entanto, pouco se sabe sobre o comportamento de várias espécies amazônicas quando submetidas a tratamentos de correçáo do solo e de que forma a elevação do $\mathrm{pH}$ e as conseqüências decorrentes disso podem influenciar na produção de mudas e no crescimento inicial dessas espécies.

Este trabalho foi desenvolvido com o objetivo de avaliar o efeito de doses crescentes de corretivo da acidez do substrato sobre o crescimento e a absorção de nutrientes por mudas de mogno, visando estabelecer uma dose de corretivo em que as mudas de mogno apresentem maior desenvolvimento vegetativo.

\section{MATERIAL E MÉTODOS}

O experimento foi conduzido no Viveiro Florestal da Faculdade de Ciências Agrárias (FCA) da Universidade Federal do Amazonas (UFAM), no período de setembro de 2002 a agosto de 2003.

O material usado como substrato foi coletado na camada sub-superficial de um Latossolo Amarelo álico muito argiloso, localizado no Setor Sul do Campus Universitário da UFAM, cujas coordenadas UTM são 21M0168944; 9637166.

Após a coleta o material foi destorroado e colocado para secar ao ar livre e passado em uma peneira com malha de quatro milímetros de abertura e colocado em sacos plásticos.

Amostras do material foram submetidas à análise química como descrito a seguir: o $\mathrm{pH}$ em $\mathrm{H}_{2} \mathrm{O}$ foi determinado na relação solo:solução $1 \mathrm{~g}: 2,5 \mathrm{ml}$. Os teores de $\mathrm{Al}^{3+}, \mathrm{Ca}^{2+}$ e $\mathrm{Mg}^{2+}$ foram extraídos com KCl $1 \mathrm{~mol} \mathrm{~L}^{-1}$ e determinados por titulometria. Os teores de $\mathrm{P}$ e K disponíveis foram extraídos pela solução Mehlich-1 e quantificados por colorimetria em espectrofotômetro de absorção molecular e fotometria de chama, respectivamente. $\mathrm{H}+\mathrm{Al}$ foram extraídos com solução de acetato de cálcio $0,5 \mathrm{~mol}$ $\mathrm{L}^{-1} \mathrm{pH} 7,0 . \mathrm{O}$ teor de carbono orgânico total foi determinado pelo método de Walkley \& Black. Essas determinaçōes foram feitas pelo método analítico descrito em EMBRAPA (1997).

A partir dos valores obtidos calculou-se a soma de bases, capacidade de troca de cátion efetiva, capacidade de troca de cátion total e saturação por alumínio. Os resultados da caracterização química e teor de argila do substrato são apresentados na tabela 1 .

O delineamento experimental utilizado foi o de blocos casualizados constituído de sete tratamentos e cinco repetições, num total de 35 parcelas, sendo cada parcela constituída de três plantas. Os tratamentos corresponderam a doses crescentes de corretivo equivalentes a $0 ; 0,5 ; 1,0 ; 2,0 ; 2,5 ; 3,0$ e 5,0 t.ha $^{-1}$. O corretivo utilizado foi uma mistura de carbonato de cálcio e carbonato de magnésio p.a., na relação $\mathrm{CaCO}_{3}: \mathrm{MgCO}_{3}$ de 4:1, com PRNT igual a $100 \%$. Após a aplicação do corretivo, o substrato ficou incubado por 30 dias para que ocorresse a reação de neutralização da acidez. Procedeu-se, após este período, as aplicações dos fertilizantes.

Tabela 1 - Características químicas e teor de argila do solo utilizado como substrato para a produção de mudas de mogno.

\begin{tabular}{|c|c|c|c|c|c|c|c|c|c|c|}
\hline \multirow[t]{2}{*}{$\mathrm{pH} \mathrm{H}_{2} \mathrm{O}$} & $P$ & $\mathrm{~K}$ & $\mathrm{Al}^{3+}$ & $\mathrm{H}^{+} \mathrm{Al}$ & $\mathrm{Ca}^{2}+\mathrm{Mg}^{2+}$ & $\mathrm{T}$ & $t$ & \multirow{2}{*}{$\%$} & \multirow{3}{*}{$\begin{array}{c}\mathrm{V} \\
2,46\end{array}$} & СОT Argila \\
\hline & \multicolumn{2}{|c|}{$\mathrm{mg} / \mathrm{kg}$} & \multicolumn{5}{|c|}{$\mathrm{cmol}_{\mathrm{c}} \mathrm{kg}^{-1}$} & & & $\mathrm{~g} \mathrm{~kg}^{-1}$ \\
\hline 5,5 & 1 & 24 & 1,2 & 6,35 & 0,10 & 6,51 & 1,36 & 88,24 & & 14,4 \\
\hline
\end{tabular}


Os fertilizantes usados foram: uréia, superfosfato triplo e cloreto de potássio em doses equivalentes a 0,1; 0,25 e 0,15 g $\mathrm{kg}^{-1}$ de substrato de $\mathrm{N}, \mathrm{P}_{2} \mathrm{O}_{5}$ e $\mathrm{K}_{2} \mathrm{O}$, respectivamente. Como fonte de micronutrientes utilizou-se a FTE-BR12, em dose equivalente a $15 \mathrm{~kg} \cdot \mathrm{ha}^{-1}$.

As doses dos fertilizantes foram selecionadas em função das características do solo e das necessidades nutricionais de algumas espécies florestais, de acordo com Tucci et al., (2004). A incorporação dos fertilizantes, exceto o nitrogenado, foi realizada manualmente. Após a aplicação dos fertilizantes, o substrato foi transferido para embalagens com capacidade de $3,5 \mathrm{~kg}$. O adubo nitrogenado foi solubilizado em água e aplicado em cobertura 35 dias após a repicagem das plântulas.

Durante a condução do ensaio, as plantas foram regadas diariamente e a umidade foi controlada por pesagem e o teor correspondeu aproximadamente à capacidade de campo para Latossolos, que éde cerca de $30 \%$ do peso do solo seco, conforme sugerido por Tucci (1996).

As sementes utilizadas na produção das mudas foram coletadas de espécimes adultos em três locais distintos na cidade de Manaus (AM). O primeiro lote foi coletado na área de uma empresa do Distrito Industrial. O segundo lote na Vila Militar da Base Aérea e o terceiro lote num terreno ao lado da Superintendência da Zona Franca de Manaus.

As sementes das diversas procedências foram misturadas e apresentavam em média $51 \%$ de umidade, de acordo com Brasil (1992). Posteriormente, foram secas ao ar, acondicionadas em sacos plásticos e armazenadas em câmara fria.

As sementes foram colocadas para germinar em copos descartáveis de $300 \mathrm{ml}$, contendo areia lavada em solução $0,1 \%$ de hipoclorito de sódio. A repicagem das plântulas ocorreu 28 dias após a germinação, quando estas atingiram aproximadamente $15 \mathrm{~cm}$. Não foram observadas pragas e doenças e o único trato cultural utilizado foi a retirada manual de plantas invasoras. As mudas de mogno permaneceram em viveiro coberto com "sombrite", com $60 \%$ de sombreamento, por um período de 90 dias.

Ao final do período de ensaio as mudas foram coletadas e em seguida separadas as partes aéreas das raízes. As raízes foram lavadas em água corrente para a retirada do excesso de solo, utilizando-se peneira para evitar perda de material vegetal. O material vegetal foi separado por tratamento, seco em estufa de circulação forçada a $70^{\circ} \mathrm{C}$, até atingir peso constante; pesado e moído separadamente. Posteriormente, submetido às análises químicas para a determinação dos teores de N, P, K, Ca, Mg, Fe, Cu, Zn e Mn da parte aérea e da raiz. As análises foram realizadas no Laboratório de Solos da EMBRAPA-CPAA, segundo procedimento analítico descrito por Malavolta et al. (1989). Os conteúdos de N, P, K, $\mathrm{Ca}$ e $\mathrm{Mg}$ foram estimados a partir dos teores totais desses elementos.
Também foram avaliadas as características de crescimento por meio da altura da planta, medida desde a inserção dos cotilédones até a gema apical; o diâmetro do colo (DC), medido na base da planta rente ao substrato; a matéria seca da parte aérea (MSPA) e da raiz (MSR) e a relação parte aérea/raiz (PA/R).

Os dados obtidos foram submetidos à análise estatística, visando ajuste de um modelo de regressão considerando-se as características avaliadas como variáveis dependentes das doses de corretivo aplicadas. No entanto, não se conseguiu ajuste de modelo de regressão linear para os resultados obtidos. Os dados, após análise de variância, foram submetidos ao teste de média para as variáveis que apresentaram efeito significativo dos tratamentos.

\section{RESULTADOS E DISCUSSÃO}

\section{ABSORÇÃO DE NUTRIENTES}

A calagem influenciou significativamente o conteúdo total dos macronutrientes avaliados, em comparação à sua ausência (Tabela 2). Os resultados mais significativos foram observados na aplicação das doses 0,5 e 2,5 t/ha. Várias são as razōes que explicam o efeito da calagem sobre o aumento da absorção de nutrientes em função do aumento da mineralização da matéria orgânica do solo e devido ao maior aproveitamento dos fertilizantes aplicados (Malavolta, 1981; Osaki, 1991; Raij, 1991).

Os valores observados para conteúdo de $\mathrm{N}$ mostram que 2,5 t.ha ${ }^{-1}$ foi superior à sua ausência e a 2,0 t.ha ${ }^{-1}$, porém, foi estatisticamente igual aos demais tratamentos. De acordo com Malavolta \& Romero (1975) a prática de calagem aumenta a disponibilidade de $\mathrm{N}$ e outros nutrientes.

O maior conteúdo de $\mathrm{P}$ nas mudas de mogno foi observado com a aplicação de 2,5 t.ha" ${ }^{-1}$ de corretivo (Tabela 2), evidenciando que a aplicação de corretivo afetou a absorção do P. Esses resultados coincidem com os encontrados por Fernandez et al. (1996) para mudas de Mimosa tenuifolia, que observaram

Tabela 2 - Conteúdo total dos macronutrientes em mudas de mogno submetidas a doses crescentes de corretivo do solo.

\begin{tabular}{cccccc}
\hline Corretivo & $\mathrm{N}$ & $\mathrm{P}$ & $\mathrm{K}$ & $\mathrm{Ca}$ & $\mathrm{Mg}$ \\
\hline t.ha $^{-1}$ & & \multicolumn{4}{c}{ g.planta-1 } \\
\cline { 2 - 6 } 0,0 & $15,75 \mathrm{c}$ & $1,06 \mathrm{e}$ & $12,60 \mathrm{c}$ & $8,55 \mathrm{~b}$ & $1,09 \mathrm{~b}$ \\
0,5 & $30,24 \mathrm{ab}$ & $2,45 \mathrm{~b}$ & $31,91 \mathrm{ab}$ & $12,89 \mathrm{ab}$ & $1,53 \mathrm{ab}$ \\
1,0 & $25,22 \mathrm{abc}$ & $2,23 \mathrm{~b}$ & $25,51 \mathrm{abc}$ & $11,55 \mathrm{ab}$ & $1,22 \mathrm{~b}$ \\
2,0 & $18,85 \mathrm{bc}$ & $1,67 \mathrm{~d}$ & $18,48 \mathrm{bc}$ & $8,80 \mathrm{~b}$ & $1,00 \mathrm{~b}$ \\
2,5 & $33,64 \mathrm{a}$ & $2,90 \mathrm{a}$ & $35,77^{\mathrm{a}}$ & $17,81 \mathrm{a}$ & $2,02 \mathrm{a}$ \\
3,0 & $20,15 \mathrm{abc}$ & $1,79 \mathrm{~cd}$ & $22,51 \mathrm{abc}$ & $9,52 \mathrm{~b}$ & $1,16 \mathrm{~b}$ \\
5,0 & $25,36 \mathrm{abc}$ & $2,08 \mathrm{bc}$ & $29,60 \mathrm{ab}$ & $12,71 \mathrm{ab}$ & $1,56 \mathrm{ab}$ \\
\hline
\end{tabular}

Letras distintas na mesma coluna diferem entre si pelo teste de Tukey, a $5 \%$ de probabilidade. 
resposta ao $\mathrm{P}$ em função das doses de calcário, indicando que houve efeito da interação calcário x fósforo. Segundo Raij \& Quaggio (1984), a calagem favorece o aproveitamento do fósforo do solo. Na medida em que o $\mathrm{pH}$ diminui, isto é, abaixo de 5,5, a disponibilidade do $\mathrm{P}$ também diminui, devido a fixação dos radicais fosfatos pelos íons $\mathrm{Al}^{3+} \mathrm{e} \mathrm{Fe}^{3+}$, que se encontram em grandes quantidades no solo quando o $\mathrm{pH}$ é baixo (Osaki, 1991). Com a prática da calagem o $\mathrm{pH}$ tende a aumentar e, consequentemente, a disponibilidade do fósforo também aumenta.

Os resultados apresentados na tabela 2 mostram que a calagem afetou a absorção de potássio, uma vez que com a aplicação de 2,5 t.ha ${ }^{-1}$, as mudas apresentaram conteúdo total de $\mathrm{K}$ superior ao da testemunha e da dose de 2,0 t.ha ${ }^{-1}$. Silva (1983) descreve que a calagem foi essencial para melhorar os efeitos do potássio e boro na produção da cultura do algodoeiro. Silva (1996) observou que o cedro (Cedrela odorata) respondeu à adubação potássica, diferente da copaíba, jatobá e pau pereira, que mostraram pequeno incremento na matéria seca quando aplicado potássio.

Furtunato (2001) observou que a calagem do solo proporciona aumento na concentração de nitrogênio, cálcio e magnésio nas raízes e parte aérea de grápia (Apuleia leiocarpa), bem como potássio na parte aérea e diminuiu a concentração de manganês nas raízes e parte aérea.

A maior absorção de $\mathrm{Ca}^{2+} \mathrm{e} \mathrm{Mg}^{2+}$ em função da calagem é devido à incorporação do corretivo no solo, que diminui a acidez e, conseqüentemente, diminui o teor de $\mathrm{Al}^{3+}$ trocável, facilitando a absorção dos nutrientes. Os conteúdos totais de $\mathrm{Ca}$ e $\mathrm{Mg}$ em mudas de mogno apresentaram valores estatisticamente superiores com a aplicação de $2,5 \mathrm{t} / \mathrm{ha}$, porém não houve diferença significativa com a dose 0,$5 ; 1,0$ e 5,0 t.ha ${ }^{-1}$ para Ca e 0,5 e 5,0 t.ha ${ }^{-1}$ para $\mathrm{Mg}$ (Tabela 2). Caires \& Rosolem (1998) observaram, em mudas de amendoim, que a calagem aumentou os teores de cálcio e magnésio trocáveis. Isto foi atribuído ao aumento da densidade de raízes nos primeiros $20 \mathrm{~cm}$ de profundidade e devido à melhoria da fertilidade do solo, principalmente dos teores de Ca. Em vários trabalhos foram encontrados resultados positivos quando do uso de corretivo pela elevação da concentração de $\mathrm{Ca}^{2+} \mathrm{e} \mathrm{Mg}^{2+}$ trocáveis e diminuição da acidez do solo (Novais, 1979; Barros et al., 1981; Gonçalves et al., 1986), o que favorece o desenvolvimento do sistema radicular (Gonçalves \& Mello, 2000).

A calagem afetou a absorção de ferro, pois se observa na dose de 2,0 t.ha ${ }^{-1}$ de calcário, valor superior ao da dose 5,0 t.ha ${ }^{-1}$, ou seja, com o aumento crescente de calcário houve uma redução no teor de Fe na matéria seca da parte aérea (Tabela 3). Tal efeito é comprovado na literatura (Malavolta, 1985; Quaggio, 1985). Para o manganês, os resultados diferiram da literatura, pois se esperava redução (Malavolta \& Romero, 1975; Malavolta, 1980) com a elevação do $\mathrm{pH}$, o que não ocorreu, pois se observou aumento da absorção desse elemento (Tabela 3 ). $\mathrm{O}$ fato pode ser explicado pela utilização de uma fonte desse elemento na forma de FTE que, segundo Lopes (1987), tem efeito em ampla faixa de $\mathrm{pH}$.

A absorção do Cu e Zn não foram afetadas pela calagem, pois os valores correspondentes às parcelas onde se aplicou o corretivo foram estatisticamente iguais aos observados na ausência.

\section{CRESCIMENTO DAS MUDAS}

As mudas de mogno não apresentaram diferença em altura, demonstrando que a calagem não foi capaz de afetar o seu crescimento, pois o tratamento sem calagem apresentou altura estatisticamente igual aos demais (Tabela 4). Esses resultados diferem dos encontrados por Barros (2001) e Pinto et al. (2000), que observaram respostas positivas da aplicação de corretivo sobre a altura das plantas de mogno. Esta diferença pode estar relacionada aos graus de sombreamento em que as mudas foram submetidas, pois os referidos trabalhos foram conduzidos em casa-de-vegetação. Desta forma as condiçōes de sombreamento diferiram do experimento em pauta, que foi conduzido em viveiro. Tal fato pode explicar a diferença encontrada nos experimentos.

O maior valor de diâmetro foi observado com a aplicação de 2,5 t.ha ${ }^{-1}$, porém apenas foi estatisticamente superior nas doses de 2,0 e 3,0 t.ha ${ }^{-1}$ (Tabela 4). Isto pode estar relacionado com a absorção de nutrientes, pois o tratamento em que o diâmetro foi maior também se observa maior valor na absorção de nutrientes (Tabela 2). Segundo Caíres \& Rosolem (1996) a calagem melhora as condiçôes de $\mathrm{pH}$ do solo e com isto observou-se aumento dos teores de nitrogênio em diversas partes da planta. Os autores também afirmam que no caule o aumento nos teores de nitrogênio ocasionou aumento na absorção de fósforo, favorecendo ganhos em diâmetro.

Tabela 3 - Teor de micronutrientes na matéria seca da parte aérea em mudas de mogno submetidas a doses crescentes de corretivo do solo.

\begin{tabular}{ccccc}
\hline Corretivo & $\mathrm{Cu}$ & $\mathrm{Fe}$ & $\mathrm{Mn}$ & $\mathrm{Zn}$ \\
\hline t.ha $^{-1}$ & \multicolumn{4}{c}{$\mathrm{mg} \cdot \mathrm{kg}^{-1}$} \\
\cline { 2 - 5 } 0,0 & 9,0 & $207,60 \mathrm{ab}$ & $9,40 \mathrm{~b}$ & 25,40 \\
0,5 & 5,40 & $208,80 \mathrm{ab}$ & $24,0 \mathrm{ab}$ & 23,0 \\
1,0 & 6,0 & $229,60 \mathrm{ab}$ & $21,60 \mathrm{ab}$ & 24,40 \\
2,0 & 5,0 & $259,0 \mathrm{a}$ & $16,60 \mathrm{ab}$ & 23,40 \\
2,5 & 5,0 & $195,40 \mathrm{ab}$ & $31,0 \mathrm{a}$ & 22,40 \\
3,0 & 5,60 & $206,60 \mathrm{ab}$ & $23,80 \mathrm{ab}$ & 23,20 \\
5,0 & 6,0 & $188,20 \mathrm{~b}$ & $30,80 \mathrm{a}$ & 23,60 \\
\hline
\end{tabular}

Letras distintas na mesma coluna diferem entre si pelo teste de Tukey, a $5 \%$ de probabilidade. 
Os resultados em matéria seca da parte aérea mostram que apenas nos tratamentos em que se aplicaram 0,5 e 2,5 tha ${ }^{-1}$ produção foi superiores à da ausência (Tabela 4). Dias et al. (1991) observaram resposta em produção de matéria seca das folhas em Acacia manguim à adubação com fósforo e nitrogênio, o mesmo não ocorrendo para potássio e calagem. Os resultados encontrados para matéria seca de raiz demonstraram que a calagem afeta a característica (Tabela 4). Entretanto os resultados para matéria seca da raiz demonstram uma grande amplitude de variação de $91 \%$, entre o menor resultado $(1,93 \mathrm{~g})$ e o maior $(3,69 \mathrm{~g})$. O maior valor de matéria seca da raiz foi observado com a dose de 2,5 tha ${ }^{-1}$ o que também coincidiu com o maior conteúdo de cálcio (Tabela 2). Segundo (Vale et al., 1996) o nutriente que mais limita o crescimento do sistema radicular de espécies florestais em solo é o cálcio.

As mudas de mogno cultivadas no substrato sem calagem apresentaram produção de matéria seca total da ordem de 11,55 $\mathrm{g}$ (Tabela 4). Quando o corretivo foi incorporado, as plantas tiveram produção relativa nas doses 0,$5 ; 1,0 ; 2,0 ; 2,5 ; 3,0 ; 5,0$ t.ha ${ }^{-1}$ de $160 \%, 144 \%, 101 \%, 179 \%, 103 \%$ e $130 \%$, respectivamente. Furtini Neto et al. (1999) também verificaram aumento na matéria seca total de várias espécies, em função da calagem. Segundo esses autores, estes resultados são importantes na medida em que se ressaltam diferentes reaçōes das espécies florestais às condições de acidez do solo e à capacidade de resposta dessas espécies à aplicação de corretivos.

Para a relação parte aérea/raiz, observam-se diferenças apenas entre a testemunha e a maior dose (Tabela 4). Tal fato pode ser explicado pela quantidade de água e nutrientes aplicados, no tratamento com a maior dose de corretivo, que não restringiu o crescimento nem da parte aérea nem da raiz. Quando não há restrição de crescimento no solo as plantas em seu estágio inicial de crescimento priorizaram o desenvolvimento da parte aéreo causado uma maior produção de matéria seca da parte aérea, aumentando a relação parte aérea/raiz com a maior dose.

Tabela 4 - Crescimento em altura, diâmetro, produção de matéria seca da parte aérea (MSPA), matéria seca da raiz (MSR), matéria seca total (MST) e relação parte aérea/raiz (PA/R) das mudas de mogno submetidas a doses crescentes de corretivo do solo.

\begin{tabular}{ccccccc}
\hline Corretivo & Altura & Diâmetro & MSPA & MSR & MST & PA/R \\
\hline t.ha $^{-1}$ & $\mathrm{~cm}$ & $\mathrm{~cm}$ & $\mathrm{~g}$ & $\mathrm{~g}$ & $\mathrm{~g}$ & \\
\hline 0,0 & 26,32 & $4,80 \mathrm{ab}$ & $8,78 \mathrm{c}$ & $2,01 \mathrm{ab}$ & $11,55 \mathrm{~b}$ & $3,22 \mathrm{~b}$ \\
0,5 & 29,10 & $5,04 \mathrm{ab}$ & $15,23 \mathrm{ab}$ & $3,24 \mathrm{ab}$ & $18,48 \mathrm{ab}$ & $5,30 \mathrm{ab}$ \\
1,0 & 29,84 & $4,94 \mathrm{ab}$ & $13,47 \mathrm{abc}$ & $3,20 \mathrm{ab}$ & $16,67 \mathrm{ab}$ & $4,19 \mathrm{ab}$ \\
\hline 2,0 & 27,80 & $4,14 \mathrm{~b}$ & $9,73 \mathrm{bc}$ & $1,93 \mathrm{~b}$ & $11,67 \mathrm{~b}$ & $5,04 \mathrm{ab}$ \\
\hline 2,5 & 32,48 & $5,52 \mathrm{a}$ & $16,96 \mathrm{a}$ & $3,69 \mathrm{a}$ & $20,65 \mathrm{a}$ & $4,86 \mathrm{ab}$ \\
3,0 & 28,18 & $4,54 \mathrm{~b}$ & $9,81 \mathrm{bc}$ & $2,05 \mathrm{ab}$ & $11,86 \mathrm{~b}$ & $4,76 \mathrm{ab}$ \\
\hline 5,0 & 29,48 & $4,62 \mathrm{ab}$ & $12,97 \mathrm{abc}$ & $2,05 \mathrm{ab}$ & $15,04 \mathrm{ab}$ & $6,31 \mathrm{a}$ \\
\hline
\end{tabular}

Letras distintas na mesma coluna diferem entre si pelo teste de Tukey, a $5 \%$ de probabilidade.
Gonçalves \& Mello (2000) descreveram que a relação parte aérea/ raiz diminui quando a quantidade de fotoassimilados aumenta nas raízes, devido à baixa disponibilidade de água e nutrientes. Segundo os autores, o maior dispêndio de energia para produção de raízes reduz a produtividade de madeira e outros produtos florestais.

\section{CONCLUSÕES}

Para as características de crescimento em mudas de mogno observou-se que a calagem afetou positivamente o diâmetro, matéria seca da parte aérea, matéria seca da raiz, matéria seca total e relação parte aérea/raiz.

A calagem afetou positivamente a absorção de $\mathrm{N}, \mathrm{P}, \mathrm{K}, \mathrm{Ca}$, $\mathrm{Mg}, \mathrm{Mn}$ e negativamente a de $\mathrm{Fe}$.

A primeira recomendação de calagem para esta espécie, quando se utiliza subsolo ácido e de baixa fertilidade natural, pode ser de $0,5 \mathrm{t} / \mathrm{ha}$ ou $0,250 \mathrm{~kg}$ de calcário com $100 \%$ de PRNT para cada $1000 \mathrm{~kg}$ de substrato.

\section{BIBLIOGRAFIA CITADA}

Barros, N.F.; Braga, J.M.; Brandi, R.M.; Defelipo, B.V. 1981. Produção de eucalipto em solos de cerrado em resposta à aplicação de NPK e de B e Zn. Revista Árvore, v.5, p.90-113.

Barros, J.G. 2001. Adubação e calagem para formação de mudas de mogno (Swietenia macrophylla King). Dissertação de Mestrado, Universidade Federal do Amazonas, Manaus, Amazonas. 63pp

Brasil. 1992. Regras para análises de sementes. Ministério da Agricultura. Secretaria Nacional de Defesa Agropecuária. Brasília. 365pp.

Caíres, E.F.; Rosolem, C.A. 1996. Mineral nutrition of peanuts as affected by liming: Nitrogen. Cientific., 24(2): 371-384.

Caíres, E.F.; Rosolem, C.A. 1998. Correção da acidez do solo e desenvolvimento do sistema radicular do amendoim em função da calagem. Bragantia, 57(1).

Carneiro, J.G.A. 1995 Produção e controle de qualidade de mudas de espécies florestais. Curitiba: UFPR/FUPEF. 451pp.

CFSEMG. 1989. Recomendação para uso de corretivos e fertilizantes no Estado de Minas Gerais. $4^{\mathrm{a}}$ aprox. Lavras. 159pp.

Dias, L.E.; Alvarez, V.H.V.; Brienza, Jr.S. 1991. Formação de mudas de Acacia mangium Willd: II: Respostas a nitrogênio e potássio. Revista Árvore, 15(1): 11-22.

EMBRAPA. 1979. Manual de métodos de análise de solo. Rio de Janeiro: Serviço Nacional de Levantamento e Classificação de Solos, 1.

Fernandez, J.Q.P.; Ruivo, M. de L.P.; Dias, L.E.; Costa, J.P.V.; Diaz, R.R. 1996. Crescimento de Mimosa tenuiflora submetida a diferentes níveis de calagem e doses de fósforo, potássio e enxofre. Revista Arvore. 20 (4): 425-431.

Furtini Neto, A.E.; Resende, A.V.; Vale, F.R.; Silva, I.R. 1999. Liming efectes on growth of native woody species form Brazilian Savannah. Pesq. agropec. bras., 34(5): 829-837. 
Furtunato, R.P. 2001. pH do solo e toxidez de aluminio no crescimento e nutrição mineral de mudas de grápia (Apuleia leiocarpa). Dissertação de Mestrado, Universidade Federal de Santa Maria. Santa Maria, Rio Grande do Sul. 59pp.

Gonçalves, J.L.M.; Barros, N.F.; Neves, J.C.L.; Novais, R.F. 1986. Níveis críticos de fósforo no solo e na parte aérea de eucalipto na presença e ausência de calagem. Revista Arvore, 10: 91-104.

Gonçalves, J.L.M.; Mello, S.L. 2000. O sistema radicular das árvores. In.: Nutrição e fertilização florestal. Piracicaba: IPEF. 427pp.

Lopes, A.S. 1987. Micronutrientes: dinâmica e disponibilidade no solo. In.: Francisco Maximino Fernandes e Vinícius Martins do Nascimento (Eds). Curso de atualização em fertilidade do solo. Fundação Cargill. Campinas, 418pp.

Malavolta, E., Romero, J.P. (Coord) 1975. Manual de adubação. ANDA. São Paulo, 2.ed. 345pp.

Malavolta, E. 1980. Elementos de nutrição mineral. Ed. Ceres. São Paulo. 251pp.

Malavolta, E. 1981. Manual de química agrícola: adubos e adubaçōes. $3^{a}$ ed. São Paulo. Ed. Ceres. 596pp.

Malavolta, E. 1985. Reação do solo e crescimento das plantas. In.: Seminário sobre corretivos agrícola. Fundação Cargill. Campinas SP. 375pp.

Malavolta, E., Vitti, G.C., Oliveira, S.A. 1989. Avaliação do estado nutricional de plantas: princípios e aplicaçôes. POTAFOS. Piracicaba. 201pp.

Novais, R.F. 1979. Calagem e adubação NPK na produção de mudas de Eucalipto (Eucaliptus grandis W. Hill ex Maiden). Viçosa: Boletim Técnico SIF, 2: 27-66.

Osaki, F. 1991. Calagem e adubação. 2. ed. Instituto Brasileiro de Ensino Agrícola. Campinas, 503pp.
Paiva, H.N.; Gomes, J.M. 2000. Viveiros florestais (Cadernos didáticos). 2.ed Universidade Federal de Viçosa, Viçosa, Minas Gerais. 69pp.

Pinto, F.P.da S.; Tucci, C.A.F.; Barros, J.G. 2000. Calagem e adubação na formação de mudas de mogno. In.: IX Jornada de Iniciação Cientifica da Universidade do Amazonas. Manaus, AM. Resumos, p.5.

Quaggio. J.A. 1985. Respostas das culturas à calagem. In: Seminário sobre corretivos agrícolas. Fundação Cargill. Campinas. 375p.

Raij, B. Van. 1991. Fertilidade do solo e adubação. Piracicaba: Ceres, Potafos. 343p.

Raij, B. Van.; Quaggio, J.A. 1984. Uso eficiente de calcário e gesso na agricultura. In.: Espinoza, W. \& Oliveira, A.J. de (Eds). Anais do Simpósio sobre Fertilizantes na Agricultura Brasileira. Brasília, EMBRAPA - DEP. 641p.

Silva, N.M. da. 1983. Acidez do solo e calagem para algodoeiro. In: Raij, B. V.; bataglia, O.C.; Silva, N.M. da. (Coord). Acidez e calagem no Brasil - Simpósio, Campinas. Sociedade Brasileira de Ciência do Solo. p. 259-276.

Silva, I.R. 1996. Crescimento inicial, absorção de macronutrientes e eficiência nutricional em espécies florestais nativas submetidas à adubação potássica. Dissertação de Mestrado. Universidade Federal de Lavras, Lavras, Minas Gerais. 57pp.

Silva, A. R. M. da. 2004. Calagem para a formação de mudas de mogno (Swietenia macrophylla King) e sumaúma (Ceiba pentandra L. Gaertn). Dissertação de Mestrado. Universidade Federal do Amazonas, Manaus, Amazonas. Xxpp.

Tucci, C.A.F. 1996. Estimativa da necessidade de calagem para solos da Amazônia. Tese de Professor Titular. Universidade Federal do Amazonas, Manaus, Amazonas. 46pp.

Tucci, C.A.F., Hara, F. A. dos S., Freitas, R. O. de. 2004. Adubação e calagem para a formação de mudas de sumaúma (Ceiba pentandra L. Gaertn). Revista de Ciências Agrárias e Ambientais da UFAM, 11(2/2).

Vale, F.R.; Furtini Neto, A.E.; Renó, N.B.; Fernandes, L.A.; Resende, A.V. 1996. Crescimento radicular de espécies florestais em solo ácido. Pesquisa Agropecuária Brasileira, 31(9): 609-616.

Recebido em 05/10/2004

Aceito em 16/05/2007 